\title{
Guardar armamento bajo medidas de seguridad prevendría suicidios y heridas no intencionales
}

\section{Objetivo}

Evaluar la asociación de medidas específicas de seguridad en el almacenamiento del armamento doméstico, y el riesgo de suicidio y heridas no intencionales por armas de fuego en niños y adolescentes.

\section{Diseño}

Estudio caso-control.

\section{Lugar}

37 condados y cinco centros de trauma de Estados Unidos.

\section{Casos y controles}

Los casos fueron definidos como incidentes en los cuales un niño o adolescente menor a 20 años había tenido acceso a un arma de fuego y se disparó (intencionalmente o no) o disparó a otro individuo de manera accidental. Los controles se eligieron sobre la base de rastreo telefónico aleatorizado de hogares con, al menos, un arma de fuego y con niños o adolescentes viviendo en ellos, o de visita.

\section{Evaluación de la exposición}

Se evaluaron las siguientes exposiciones de importancia: 1) si el arma de fuego había sido guardada descargada; 2) si el arma de fuego había sido guardada bajo llave o con un cierre extrínseco; 3 ) si la munición había sido guardada bajo llave; 4) si la munición había sido almacenada separada del arma de fuego

\section{Medición de resultados principales}

Se incluyeron 106 casos (82 suicidios y 24 accidentes) y 480 controles. Se evaluó la asociación a través de un modelo multivariable de regresión logística.*

\section{Resultados principales}

Luego de ajustar* por potenciales confundidores, como lugar de residencia, edad, características de los entrevistados, tipo y número de armas, y finalidad de las mismas, se obtuvieron los resultados que se resumen en el cuadro 1.

Cuadro 1: asociación entre la exposición a armas de fuego y/o a municiones; e incidentes en los que el menor de edad tuvo acceso al arma y esta se disparó.

\begin{tabular}{l|c|c|c|c}
\multicolumn{2}{c|}{ Exposición } & Casos & Controles & OR (IC95\%) \\
\cline { 2 - 5 } Arma & Descargada & $64(66 \%)$ & $429(90,7 \%)$ & $0,30(0,16-0,56)$ \\
\cline { 2 - 5 } & Bajo llave & $34(32,4 \%)$ & $274(57,7 \%)$ & $0,27(0,17-0,45)$ \\
\hline \multirow{2}{*}{ Munición } & Bajo llave & $24(24,2 \%)$ & $222(48,2 \%)$ & $0,39(0,23-0,66)$ \\
\cline { 2 - 5 } & Separada & $41(41,4 \%)$ & $304(65,2 \%)$ & $0,45(0,34-0,93)$ \\
\hline
\end{tabular}

\section{Conclusiones}

Guardar el arma bajo llave, descargada, y almacenar la munición bajo llave, separada del arma, son cuatro medidas que están asociadas a un efecto protector, y sugieren una estrategia plausible para reducir este tipo de lesiones en hogares con niños y adolescentes.

Fuente de financiamiento: Centers for Disease Control and Prevention

\section{Comentario}

Las armas de fuego están presentes en alrededor de un tercio de los hogares en Estados Unidos. Si bien no hay cifras exactas, la prevalencia de las mismas se ha medido utilizando diversos "proxies" o indicadores indirectos ${ }^{1}$. A través de ellos se concluyó, por ejemplo, que en las regiones de dicho país en las que la prevalencia de armamento doméstico era mayor, se registraba un número extremadamente alto de suicidios, homicidios y heridas no intencionales por armas de fuego entre niños de 5 a 14 años $^{2}$.

Los niños y adolescentes pueden estar tentados de jugar o practicar con armas de fuego, y aquellos que tienen acceso a las mismas, pueden a veces manipularlas sin supervisión de un adulto. Intuitivamente, el guardar el armamento bajo alguna medida de seguridad debería prevenir heridas y desalentar el acceso al mismo de quienes tengan intenciones suicidas. En este trabajo, Grossman y col. evaluaron, a través de un estudio caso control ${ }^{*}$, la asociación de medidas específicas de seguridad en el almacenamiento de armamento. Cada una de estas medidas de seguridad demostraron estar asociadas con reducciones en el riesgo de heridas por arma de fuego, luego de controlar por lugar de residencia, edad de los niños y adolescentes, características de los entrevistados, tipo y número de armas, y finalidad de las mismas (recreación o protección). Los resultados fueron similares tanto para intentos de suicidio como para accidentes.

Debe destacarse que estos resultados no pueden generalizarse a heridas de arma de fuego debidas a asaltos $u$ homicidios, o a situa- ciones en las que los adolescentes vivan fuera de la supervisión de los padres.

En Argentina no tenemos cifras exactas acerca de tenencia armas de fuego en hogares. Sin embargo, los niveles actuales de violencia e inseguridad deberían llevar a las autoridades sanitarias y a los profesionales de la salud en general a encuadrar dicha tenencia como un factor de riesgo a tener en cuenta. Deberían realizarse estudios de prevalencia de armas de fuego y su correlación con suicidios, accidentes y homicidios; así como también la efectividad de diversas estrategias para acotar esta problemática.

Mientras tanto, en el contexto actual, y con el objetivo de prevenir lesiones no intencionales, homicidios y/o suicidios, consideramos que debería interrogarse acerca de la tenencia de armas de fuego en el hogar durante el control periódico de salud (al igual que lo hacemos acerca del uso del cinturón de seguridad, el casco o las medidas para la prevención del embarazo no deseado, etc.).

\section{Conclusiones del comentador:}

Si bien no contamos con datos de prevalencia y de la efectividad del consejo médico parece razonable interrogar acerca de la tenencia de armas en el hogar, aconsejando en caso afirmativo, que armas y municiones sean guardadas bajo llave y en lugares separados.

\section{Referencias}

1. Household Firearm Ownership and Suicide Rates in the United States. Miller M, Azrael G, Hemenway D. Epidemiology 2.002; 13: 517-524.

2. Firearm Availability and Unintentional Firearm Deaths, Suicide, and Homicide among 5-14 year olds. Miller M, Azrael G, Hemenway D. J Trauma 2.002; 52: 267-275. 